\title{
A New Nuclear Age: An Exclusionary Global Order?
}

\author{
Amrita Chakravorty ${ }^{*}$
}

DOI: $10.21827 / 5 \mathrm{a} 6 \mathrm{af} 9 \mathrm{dfcc} 80 \mathrm{~d}$

\begin{abstract}
Keywords
NON-PROLIFERATION; DISARMAMENT; UNITED NATIONS SECURITY COUNCIL (UNSC); NUCLEAR NON-PROLIFERATION TREATY (NPT); JOINT COMPREHENSIVE PLAN OF ACTION (JCPOA); NUCLEAR SUPPLIERS GROUP WEAPON STATES (NNWSS)
\end{abstract}

\begin{abstract}
The global nuclear power play seems to be changing form and altering courses with each passing day. The world has realised the enormous destructive potential of nuclear weapons and has even made reasonable room for curbing and containing their use in the past. However, whether or not the world leaders today continue to share this wisdom is a matter of contention, as well as high concern. The recently concluded $72^{\text {nd }}$ Session of the United Nations General Assembly (UNGA) witnessed the world leaders discussing some of the most pertinent nuclear issues; however, there was no visible cohesion in their policy narratives, nor any international wisdom in their approach to these problems. The recently adopted Treaty on the Prohibition of Nuclear Weapons, on the other hand, failed to see the participation of any nuclear weapon State, or even those States within their broad umbrellas; while the Middle East once again seems to be mired in a fresh crisis, with the Iran Nuclear Deal on the verge of being de-certified and the possibility of Iran no longer being bound by its mandates. This paper attempts to analyse in brief these issues and a few more, and to bring forth the glaring discrepancies in the way they are being dealt with by the global actors.
\end{abstract}

\section{Introduction: The Present Global Issues}

The changing dynamics of the international regulation of nuclear power - be it the civilian use of nuclear energy or the storing or testing of nuclear weapons - is one of the most pertinent global issues to date. Multilateral nuclear disarmament forums today face huge obstacles, since most of them largely remain deadlocked. Several stakeholders, hence, continue to draw public attention to what has been referred to as a 'legal gap' in the nuclear non-proliferation and disarmament regime. They lament that in contrast to the regimes governing other weapons of mass destruction (biological and chemical), as well as those governing conventional weapons such as landmines and cluster munitions, the nuclear regime has failed to comprehensively prohibit the weapon in question. One of the major steps in the direction of filling this gap within the last fifty years has been the Treaty on the Prohibition of Nuclear Weapons. 122 UN Member States have acceded to this Treaty, adopting it in September 2017 in New York. It is, however, important to note that none of the nine (known to be) nuclear weapons nations - the United States (US), the United Kingdom (UK), France, Russia, China, North Korea, Israel, India and Pakistan -

\footnotetext{
The author is a Legal Officer at the Asian African Legal Consultative Organization (AALCO) Secretariat, New Delhi, India.
} 
participated in the talks leading up to this nuclear prohibitive treaty. Overall, 69 countries chose not to participate in the talks - most of whom included Asian and European countries that are under Washington's nuclear umbrella. The UK, US and France declared in a joint statement, following the UNGA adopting the new treaty on 7 July 2017, that

"[They did] not intend to sign, ratify or ever become party to it. Therefore, there will be no change in the legal obligations on [their] countries with respect to nuclear weapons". ${ }^{1}$

This was the first multilateral, legally binding instrument for nuclear disarmament to have been negotiated in 20 years. The treaty prohibits a full range of nuclear weapon-related activities, such as undertaking to develop, test, produce, manufacture, acquire, possess or stockpile nuclear weapons or other nuclear explosive devices, as well as the use or threat of use of these weapons. The new treaty has been described by many as an expression of the deep concern about the enormous risks posed by nuclear weapons and the growing frustration with the failure of nuclear armed States to fulfil their nuclear disarmament commitments.

Another relevant and fervently debated issue concerns the 2015 Joint Comprehensive Plan of Action (JCPOA), commonly known as the Iran Nuclear Deal, which once again made headlines while being extensively discussed at the $72^{\text {nd }}$ UNGA Session. Iran signed the Nuclear Non-Proliferation Treaty (NPT) in 1968. The Parliament ratified it in February 1970 (uranium enrichment was allowed under the treaty). Iran also signed the NPT's Safeguards Agreement with the International Atomic Energy Agency (IAEA). The safeguards allowed inspections for the purpose of verifying that nuclear enrichment for peaceful nuclear energy is not diverted to nuclear weapons or other nuclear explosive devices. From 2006 onwards, the UN Security Council (UNSC) began to issue a series of resolutions imposing sanctions on Iran following reports by the IAEA regarding Iran's noncompliance with its safeguards agreement under the (NPT). Sanctions were first imposed when Iran rejected the UNSC's demand that Iran suspend all uranium enrichment-related and reprocessing activities.

Ultimately, endorsed unanimously by the UNSC in 2015, the JCPOA, between its five permanent members (China, France, Russia, the UK and the US), along with Germany $(\mathrm{P} 5+1)^{2}$, the European Union (EU) and Iran, set out rigorous mechanisms for monitoring the limits on Iran's nuclear programme, whilst paving the way for lifting UN sanctions against the country. The JCPOA required constraints that seek to ensure Iran's nuclear

1 UN News Centre, "UN Conference adopts Treaty Banning Nuclear Weapons", 7 July 2017 at <un.org/apps/news/story.asp?NewsID=57139\#.WeRrvLhx2v8> (accessed 19 November 2017).

2 The initial diplomatic efforts on the Iranian nuclear issue were spearheaded by the United Kingdom, France and Germany (E3). Some of the few instances of successful engagement were the Tehran Agreed Statement of October 2003 and the Paris Agreement of November 2004 that Iran entered into with the E3. The E3 engagement process, however, hit a roadblock in the light of Iran's decision of August 01, 2005 to resume uranium conversion activities at Isfahan. The P5+1 (made up of five permanent members of the UNSC along with Germany) or a grouping also commonly known as E3+3 took forward the process of engagement spearheaded by E3 countries after the Iranian nuclear issue was referred to the UNSC by the IAEA in February 2006. Germany's involvement therefore began as part of the E3 as early as in 2003 and continued when the negotiation process was expanded to include the other three permanent members of the UNSC in 2006. 
programme will be used for purely peaceful purposes in exchange for a broad lifting of US, EU, and UN sanctions on Iran. Its 'Implementation Day' was declared by the P5+1 to be 16 January 2016, representing the completion of Iran's nuclear requirements, the entry into effect of UNSC Resolution 2231 - which endorsed the JCPOA - and the start of sanctions relief stipulated in the agreement.

The Obama Administration and other P5+1 leaders asserted that the JCPOA is the most effective means to ensure that Iran cannot obtain a nuclear weapon and that all US options to prevent Iran from developing a nuclear weapon remain available even after the key nuclear restrictions of the JCPOA expire. Critics of the JCPOA, however, expressed concerns that the extensive sanctions relief provided under the accord give Iran additional resources to extend its influence within the Middle-Eastern region and that the accord does not contain any restrictions on Iran's development of ballistic missiles. Resolution 2231, which was adopted in July 2015, prohibits arms transfers to or from Iran, but only for five years, and contains a voluntary restriction on Iran's development of nuclear-capable ballistic missiles for only up to eight years. ${ }^{3}$ The expiration of these restrictions sets the stage for Iran to emerge as a key regional actor. Therefore, the Trump Administration has begun to argue that the JCPOA does not address Iran's 'malign' activities in the region nor any other activities that the Administration considers provocative or destabilizing, such as the continued development of ballistic missiles. Administration officials have also said that these weaknesses in the agreement might lead the Administration to conclude that the agreement is not adequately serving US interests. Yet, other States within the P5+1 grouping and other US allies argue that the agreement contributes to regional stability and that the United States should continue to implement it. ${ }^{4}$

The third most pertinent issue regards the Nuclear Supplier's Group (NSG), which has 48 members and sets guidelines for nuclear trade so that transfers do not contribute to weapons proliferation. The NSG has been in the news lately for its recently concluded plenary meeting in June 2017, which ended inconclusively regarding participation by nonNPT States (particularly the bids by India and Pakistan). The People's Republic of China and a few others continued to object to India's and Pakistan's membership bids, which were

3 UNSC Resolution 2231 (2015), S/RES/2231 (2015)

Annex A: Joint Comprehensive Plan of Action (JCPOA), Vienna, 14 July, 2015

"3. Iran will continue to conduct enrichment $R \& D$ in a manner that does not accumulate enriched uranium. Iran's enrichment R\&D with uranium for 10 years will only include IR-4, IR-5, IR-6 and IR-8 centrifuges as laid out in Annex I, and Iran will not engage in other isotope separation technologies for enrichment of uranium as specified in Annex I. Iran will continue testing IR- 6 and IR-8 centrifuges, and will commence testing of up to 30 IR- 6 and IR- 8 centrifuges after eight and a half years, as detailed in Annex I".

Annex B: Statement

"6 (b). Take the necessary measures to prevent, except as decided otherwise by the UN Security Council in advance on a case-by-case basis, the supply, sale, or transfer of arms or related materiel from Iran by their nationals or using their flag vessels or aircraft, and whether or not originating in the territory of Iran, until the date five years after the JCPOA Adoption Day or until the date on which the IAEA submits a report confirming the Broader Conclusion, whichever is earlier."

4 Congressional Research Service (CRS), Katzman, K and Kerr, PK, REPORT: Iran Nuclear Agreement: Prepared for Members and Committees of Congress, Doc R43333, 15 September 2017, at $<$ fas.org/sgp/crs/nuke/R43333.pdf > (accessed 19 November 2017). 
submitted last year. The NSG, which operates by consensus, has sought to reach agreement on membership criteria for non-NPT States. ${ }^{5}$

\section{The Future of Nuclear Disarmament}

The Vienna Conference of 2014 set the ball rolling for a global movement 'to fill the gap between proliferation and elimination of nuclear weapons' with the enunciation of a Pledge on the Humanitarian Impact of Nuclear Weapons. The Pledge called upon State parties to the NPT to fulfil their Article VI obligation by pursuing effective measures «to fill the legal gap for the prohibition and elimination of nuclear weapons. This campaign, initiated in the run up to the 2015 NPT Review Conference (RevCon), gained support from a vast majority of non-nuclear weapon States attending it. This ultimately led to the adoption of the Treaty on the Prohibition of Nuclear Weapons on 7 July 2017. However, as already stated, a number of countries abstained from the negotiations. Moreover, with the NPT having a near universal jurisdiction, the need for another treaty has also been questioned.

In March 1970, the NPT came into effect and since then has provided a foundation for legal and political efforts to curb the spread of nuclear weapons. The NPT is a nearly universal treaty (except for India, Pakistan, Israel, and North Korea) and the linchpin of the global non-proliferation regime. Many critics of the NPT, however, have been of the opinion that the key implication of the US-Soviet joint draft emerging as the text of the NPT in 1968 was the absence of any effort to conceptualise the idea of non-proliferation, as either an end in itself or a means towards the anticipated end of total elimination. ${ }^{6}$ The NPT divided States into two categories namely, the Nuclear Weapon States (NWS) and the Non-Nuclear Weapon States (NNWS). The NPT in a nutshell may be described as a bargain between NWSs and NNWSs in which NWSs (the US, Russia, France, the UK and China) agreed to share nuclear technology for peaceful purposes and gradually disarm their nuclear arsenals while NNWSs agreed not to develop nuclear weapons and to accept IAEA (International Atomic Energy Agency) safeguards. ${ }^{7}$ In 1963, President Kennedy warned that 15 to 25 nations could possess nuclear weapons within a decade. However, it is mainly due to the NPT that merely nine States are known to be Nuclear Weapon States to date.

There is little doubt that the NPT regime worked well during the Cold War period, not because the regime itself exerted some direct effects on its members, but rather because the two superpowers had a convergence of interest in creating and maintaining the treaty. There was a common understanding that the world of increased nuclear weapons would be a dangerous one. The history of the NPT points to the fact that many States joined the NPT because of the persuasive powers of the Americans and the Soviets. Nuclear weapons, first

5 The NSG is not a formal organization, and its guidelines are not binding. Decisions, including on membership, are made by consensus. At the NSG plenary meeting in June, Member States designated Rafael Mariano Grossi, an Argentine diplomat and outgoing chair of the group, to lead consultations on a draft document that provides a "basis for the commitments and understanding to augment the applications of the non-NPT applicants." See Arms Control Association, Kelsey Davenport, Document Proposes Measures, which Would Apply to India and Pakistan, 11 January 2017, at < armscontrol.org/taxonomy/term/23> (accessed 18 November 2017).

6 Institute for Defense Studies and Analysis, Kumar, AV, 2017 Conference to Outlaw Nuclear Weapons: Time Ripe for a Stand-Alone Disarmament Instrument?, 4 November 2016, at <idsa.in/issuebrief/2017-conference-tooutlaw-nuclear-weapons_avkumar_041116> (accessed 18 November 2017).

7 International Policy Digest, Bano, S, Is the NPT Irrelevant?, 29 November 2014, at <intpolicydigest.org/2014/11/29/is-the-npt-irrelevant/> (accessed 18 November 2017). 
and foremost, have been procured out of security concerns. The most popular explanation why States have chosen the non-nuclear option is thus a security guaranteed by others. This proposition, however, opens more questions than it answers. For example, it cannot explain why so many 'renouncers' came from the non-aligned camp, or even the cases of the 'allied renouncers', as they had no reliable guarantees, especially in the face of the NATO nuclear programme.

A possible explanation of the NPT's success may be as follows. Interestingly, none of the 'nuclear aspirants' were democracies when the NPT was being negotiated. A significant number of these aspirants stopped their programmes during the negotiations or when the negotiations had been completed. Notably, during processes of democratisation, when young democracies struggled to prove their 'good citizenship' in order to attract international recognition and assistance, renouncing nuclear weapons appeared a particularly fit instrument to demonstrate good international behaviour. Thus, to most of them the NPT marked the line in the sand beyond which nuclear weapons aspirations lost their legitimacy. The increasingly strong non-proliferation norm shaped the discursive arena of domestic decision-making and changed the balance of influence between the proponents and opponents of a national nuclear option. The burden of proof that 'going nuclear' was the right thing to do became ever stronger. ${ }^{8}$ The NWSs, on the other hand, joined the NPT because it not only legitimized their nuclear weapons programme, but also provided them with an effective means to maintain their nuclear dominance.

The treaty provides legal justification for coercive actions when a State tries to acquire nuclear weapons under the cover of the NPT. Violation of the treaty results in economic and military sanctions and isolation. ${ }^{9}$ The NPT also requires the NWSs to

8 Muller, H, "Between Power and Justice: Current Problems and Perspectives of the NPT Regime" 34(2) Strategic Analysis (2010) 190, at <tandfonline.com/doi/pdf/10.1080/09700160903542740> (accessed 19 November 2017).

9 The IAEA Safeguards are embedded in legally binding agreements. In line with the IAEA's Statute, States accept these Safeguards through the conclusion of such agreements with the Agency. The vast majority of safeguards agreements are comprehensive safeguards agreements that have been concluded by the IAEA with non-nuclear-weapon States parties to the NPT and nuclear-weapon-free zone treaties. The IAEA has to date concluded comprehensive safeguards agreements with 174 States. Some 100 of these States have also concluded small quantities protocols to their comprehensive safeguards agreements.

All non-nuclear-weapon States party to the NPT, as well as States parties to the regional nuclearweapon-free zone treaties, are required to conclude comprehensive safeguards agreements with the IAEA. Such agreements are concluded on the basis of INFCIRC/153. The five NPT nuclear-weapon States have concluded safeguards agreements covering some or all of their peaceful nuclear activities. Under these voluntary offer agreements, facilities are notified to the IAEA by the State concerned and offered for the application of safeguards. The IAEA applies safeguards under voluntary offer agreements to nuclear material in selected facilities. Safeguards are implemented in three States that are not party to the NPT India, Pakistan and Israel - on the basis of item-specific agreements they have concluded with the IAEA.

Article III of the IAEA Statute provides the Agency with the authority, among others, to establish and administer safeguards. When the Board of Governors approves a safeguards agreement, it authorizes the Director General to conclude and subsequently implement the agreement.

Over the past 35 years the International Atomic Energy Agency's (IAEA) safeguards system under the Nuclear Non-proliferation Treaty (NPT) has been a conspicuous international success in curbing the diversion of civil uranium into military uses. It has involved cooperation in developing nuclear energy while ensuring that civil uranium, plutonium and associated plants are used only for peaceful purposes and do not contribute in any way to proliferation or nuclear weapons programs. 
negotiate in good faith to disarm their nuclear arms. It is the lack of success on the latter pledge that has prompted the NNWSs to reframe their demand for nuclear disarmament with references to the humanitarian consequences of the use of nuclear weapons, international law, and international humanitarian law. Even though the NPT remains widely popular, the reluctance of the NWSs to disarm has created a legitimacy crisis. Without the cooperation of major States, it is unlikely that the NPT will be an effective barrier against nuclear proliferation.

The reality today is that States feel compelled to strive for absolute security. Hence, it becomes individually rational to procure these weapons. Accordingly, the criticism against the NPT and the widening gap between non-proliferation and complete disarmament lead to two conflicting approaches: a) non-proliferation was to establish a global framework and structures to inhibit the further spread of nuclear weapons technology and resources alongside a series of calibrated measures, pursued in a parallel and phased manner, together leading to a conclusive disarmament process, and (b) non-proliferation could facilitate the progress towards a tipping point - a post-proliferation world - where proliferation no longer happens and sets the ideal conditions for the disarmament treaty and subsequent measures for total elimination to be initiated. ${ }^{10}$

The impetus for a nuclear weapons prohibition treaty is in many ways a reversal of the politics witnessed during the negotiations for the NPT. A vast number of the NNWSs, led by the non-aligned group, have rallied against the nuclear powers demanding a comprehensive treaty that would not only inhibit new nuclear weapon States, but also facilitate the dismantling of existing arsenals, along with steps for a ban on nuclear testing, ending fissile materials production, and allowing uninterrupted access to peaceful nuclear energy resources. The US and Soviets overlooked these demands and persuaded their allies to agree on a draft which allowed their maintenance of arsenals and incorporation of ambiguous provisions for incremental measures. Subsequently, NWSs have remained opposed to any timeline-oriented plan or stand-alone legal instrument for nuclear disarmament. The permanent members of the UNSC (P5) had issued a statement in April 2015 (days before the 2015 RevCon) reiterating their support for "an incremental, step-bystep approach (as) the only practical option for making progress towards nuclear disarmament, while upholding global strategic security and stability", arguing that a suitable security environment should be facilitated in order to make progress in all areas.$^{11}$

Recently, countries, such as India, who had rejected the NPT in 1968, have gradually begun to assume the position that they are willing to join the treaty, but solely as NWSs'. Hence, nuclear policies of developed, as well as developing States can at best be described today as 'incoherent' and 'self-serving' (not a far-cry from what it has been from the very start). India, for example, on its part has continued to maintain that the UN's Conference on Disarmament (CD) is the only

See "Safeguards Agreements), <https://www.iaea.org/topics/safeguards-agreements>. See also, "Safeguards to Prevent Nuclear Proliferation", <http://www.world-nuclear.org/informationlibrary/safety-and-security/non-proliferation/safeguards-to-prevent-nuclear-proliferation.aspx $>$.

10 Kumar, supra nt 6.

11 UN Statement, Statement by the People's Republic of China, France, the Russian Federation, the United Kingdom of Great Britain and Northern Ireland, and the United States of America to the 2015 Treaty on the Non-Proliferation of Nuclear Weapons Conference, 30 April 2015, at <un.org/en/conf/npt/2015/statements/pdf/P5_en.pdf.> (accessed 18 November 2017). 
"right place for pursuing nuclear disarmament in all its essential elements ... It has the mandate, the membership and the rules for embarking on the path to nuclear disarmament. Accordingly, India is not participating in the work of the conference on the prohibition of nuclear weapons that has started this week in New York." ${ }^{12}$

As stated by India's Permanent Representative to the CD, at the CD Plenary, on 28 March 2017. He further added

\begin{abstract}
"We live in a world full of asymmetries. Imagine if all States with asymmetry concerns started to address these concerns with such dangerous tools. Strategic trust would be impossible to sustain in such a situation and progress on disarmament and international security would grind to a halt. [...] these challenges would look less stark if the world was moving as a whole towards the complete and verifiable elimination of nuclear weapons and all other weapons of mass destruction." ${ }^{13}$
\end{abstract}

He further and notably added,

"nuclear disarmament requires a universal commitment and an agreed multilateral framework; it will have to rest on three pillars: a universal prohibition, complete elimination and international verification. India is ready to begin work on these essential elements". ${ }^{14}$

\title{
III. Where is the JCPOA Headed?
}

Despite it being repeatedly confirmed by the IAEA that Iran has been in compliance with the provisions of the nuclear deal, the reason why the current US administrative regime has been critical of the deal is, as quoted by Secretary of State Rex Tillerson, that even though Iran is in 'technical compliance', it 'is clearly in default of' the expectation that the JCPOA would also have helped address other issues, such as Iran's regional activities and continued missile testing, ${ }^{15}$ A collapse of the 2015 deal, which the current US administration has called 'an embarrassment' but which is supported by the other major powers that negotiated it with Iran, could trigger a regional arms race and stoke Middle East tensions.

Speaking at the $72^{\text {nd }}$ Session of the UNGA on 19 September 2017, the US President, Mr. Donald Trump described Iran as

"an economically depleted rogue State whose chief exports are violence, bloodshed, and chaos ... Rather than use its resources to improve Iranian lives, its oil profits go to fund Hezbollah and other terrorists that kill innocent Muslims and attack their peaceful Arab and Israeli neighbours. This wealth, which rightly belongs to Iran's

12 Permanent Mission of India to Conference on Disarmament, Statement by Ambassador Amandeep Singh Gill Permanent Representative of India to the Conference on Disarmament at the CD Plenary on March 28, 2017, 28 March 2017, at<meaindia.nic.in/cdgeneva/?pdf5909?000> (accessed 19 November 2017).

13 Ibid.

14 Ibid.

15 The Hill, Greenwood, M, Tillerson: Iran is in 'technical compliance' with the nuclear deal, 20 September 2017, at $<$ thehill.com/policy/international/351677-tillerson-iran-in-technical-compliance-with-nuclear-deal> (accessed 18 November 2017). 
people, also goes to shore up Bashar al-Assad's dictatorship, fuel Yemen's civil war, and undermine peace throughout the entire Middle East." 16

He finally concluded the US' position on the Iran nuclear deal by stating that

"We cannot let a murderous regime continue these destabilizing activities while building dangerous missiles and we cannot abide by an agreement if it provides cover for the eventual construction of a nuclear program. The Iran Deal was one of the worst and most one-sided transactions the United States has ever entered into. Frankly, that deal is an embarrassment to the United States, and I don't think you've heard the last of it - believe me."17

The US administration has since then maintained that the agreement must be changed or the US would not stick with it. ${ }^{18}$ Some of the other parties to the agreement, such as France, the UK and the EU have, however, continued to re-affirm their commitments towards the deal.

As per a recent Congressional Research Service Report, Iran has not built any new nuclear facilities or expanded the existing ones since beginning implementation of the JCPOA in January $2014 .{ }^{19}$

JCPOA requires the parties to the agreement to refrain from re-imposing the sanctions that are lifted or suspended, as long as Iran is complying. However, paragraphs 36 and 37 of the Agreement also contain a mechanism for the "snap back" of UN sanctions if Iran does not satisfactorily resolve a P5+1 inquiry about a possible breach of compliance. If the US sanctions are re-imposed (other than on the grounds of Iranian non-compliance), Iran is not bound by its nuclear commitments.

The JCPOA has had significant implications for the Middle East, and particularly for Israel and for the states of the Gulf Cooperation Council (GCC: Saudi Arabia, Kuwait, Bahrain, the United Arab Emirates, Qatar, and Oman). The JCPOA has, by most accounts, reduced any short-term threat of a nuclear-armed Iran. However, the sanctions relief of the

16 The White House, Office of the Press Secretary, Remarks by President Trump to the $72^{\text {nd }}$ Session of the United Nations General Assembly, 19 September 2017, at <whitehouse.gov/the-press-office/2017/09/19/remarkspresident-trump-72nd-session-united-nations-general-assembly> (accessed 18 November 2017).

17 Ibid.

18 Reuters, Mohammed, A and Irish, J, Iran nuclear deal must change if US to stay: Tillerson, 19 September 2017, at <reuters.com/article/us-un-assembly-france/iran-nuclear-deal-must-change-if-u-s-to-stay-tillerson-idUSK CN1BU2DB> (accessed 18 November 2017).

19 Tillerson issued this certification on July 172017 and State Department Spokesperson Heather Nauert stated on July 18 2017, that "Iran is in compliance with" the agreement. President Trump has indicated that his administration may not issue this certification in the future. (See "The JCPOA in the Trump Administration"). All official reports and statements from the United Nations, European Union, the IAEA, and the P5+1 indicate that Iran has complied with the JCPOA. See for example IAEA, Director General, REPORT: Verification and monitoring in the Islamic Republic of Iran in light of United Nations Security Council resolution 2231 (2015), GOV/2017/35, 31 August 2017; German Federal Ministry of the Interior, Brief Summary 2016 Report on the Protection of the Constitution: Facts and Trends, 8 July 2017; German Federal Foreign Office, Federal Foreign Office on the Second Anniversary of the Signing of the Agreement on Iran's Nuclear Programme, 14 July 2017, at <auswaertiges-amt.de/en/infoservice/web-archiv-node/archivepresse mitteilungen-node/170714-nuklearabkommen-iran/291414> (accessed 19 November 2017) ; Chair's statement following the 21 July 2017 meeting of the JCPOA Joint Commission, July 21 2017; United Kingdom, Statement on the Preparatory Committee for the 2020 Review Conference of the Treaty on NonProliferation of Nuclear Weapons, Vienna 2-12 May 2017. 
JCPOA has allegedly increased the economic resources available to Iran to promote its interests in the region, including the maintenance in office of Syrian President Bashar Al Assad. $^{20}$

The French President, Emmanuel Macron, in his speech at the $72^{\text {nd }}$ General Assembly Session stated that

"Our commitment to nuclear non-proliferation enabled us to achieve a solid, robust and verifiable agreement on 14 July 2015, which will enable us to ensure Iran does not acquire nuclear weapons. Terminating it today, without anything to replace it, would be a grave mistake ... For my part, I would like us to supplement this agreement with work that will help control Iran's ballistic activities, and to govern the situation after 2025 which is not covered by the 2015 agreement. We need to be more demanding, but we should in no way unpick what previous agreements have secured." 21

Some authors are of the view that a congressional decision to re-impose US nuclear sanctions could be potentially fatal to the JCPOA. It would also put the other signatories in a very difficult position, both politically and economically due to the fact that the US sanctions are mainly extra-territorial, as they would not hit Iran directly, but instead target third parties dealing with Iran. Such a step by the US would not only de-recognise Iran's compliance with the agreement ${ }^{22}$, it would also create greater instability in the Middle East, and weaken America's position in the wider global order. ${ }^{23}$

\section{The Nuclear Suppliers Group (NSG)}

As stated before, the Nuclear Suppliers Group (NSG) is a group of nuclear supplying countries that seeks to contribute to the non-proliferation of nuclear weapons through the implementation of two sets of guidelines for nuclear exports and nuclear-related exports. One of the most crucial guidelines is the "Non-Proliferation Principle", as per which a supplier, notwithstanding other provisions in the NSG Guidelines, authorises a transfer only when satisfied that the transfer would not contribute to the proliferation of nuclear weapons. The Non-Proliferation Principle seeks to cover the rare yet important cases where adherence to the NPT, or to a Nuclear Weapon Free Zone Treaty, may not by itself be a guarantee that a State will consistently share the objectives of the Treaty or that it will remain in compliance with its Treaty obligations. ${ }^{24}$

20 Ibid.

21 UN General Assembly, Speech by M. Emmanuel Macron, President of the Republic (New York, 19 September, 2017) at <diplomatie.gouv.fr/en/french-foreign-policy/united-nations/united-nations-general-assembly-sessions/ unga-s-72nd-session/article/united-nations-general-assembly-speech-by-m-emmanuel-macron-president-ofthe $>$ (accessed 18 November 2017).

${ }^{22}$ Iran is under the most extensive nuclear inspection regime in the world: in addition to implementing the IAEA Additional Protocol, it has also agreed to additional inspections including potential IAEA access to suspected undeclared nuclear facilities and military sites

23 The Wire, Cronber, T and Erasto, T, Will the US and EU go their Separate Ways on the Iran Nuclear Deal?, 13 October 2017, at <thewire.in/186800/eu-us-iran-nuclear-deal/> (accessed 18 November 2017).

24 Nuclear Suppliers Group, About the NSG, at <nuclearsuppliersgroup.org/en/about-us> (accessed 18 November 2017). 
During its initial period of existence, the NSG did not have any fixed criteria for membership. Although the group was formed as early as 1974, its first formal plenary meeting was held only in 1992 in Warsaw. At that meeting, the 27 participating governments took a decision by consensus requiring the application of the full scope of IAEA safeguards to all current and future nuclear activities as a necessary condition for all significant and new nuclear exports to NNWSs. It was only in 1993 that procedural requirements for membership were introduced in the guidelines for the first time. As per this procedure the membership of the group would initially consist of the countries adhering to the NSG Guidelines. Other countries could be invited to join the NSG by a consensus decision of its members. Although at this time, the NSG had no NPT requirements - in view of the fact that it had adopted full-scope safeguards as a condition for nuclear exports by NSG members - from 1993 onwards, the NSG had an unwritten requirement of full-scope safeguards as a precondition for NSG membership. Participation in the NSG, as of 11 May 2001, thus, consists of those participating governments adhering to and having exchanged diplomatic notes of acceptance of the guidelines for the export of nuclear material, equipment and technology, and the guidelines for transfers of nuclear related dual-use equipment, materials, software and related technology. Accordingly, the participating governments have to consider certain important factors while dealing with the possible acceptance of a new participating member. Such factors include: the applicant should have in force a legally-based domestic export control system which gives effect to the commitment to act in accordance with the Guidelines; the applicant must be a party to the NPT, the Treaties of Pelindaba, Rarotonga, Tlatelolco or Bangkok or an equivalent international nuclear non-proliferation agreement and be in full compliance with the obligations of such agreement(s); as appropriate, the applicant must have in force a full-scope safeguards agreement with the IAEA; and, lastly, be supportive of international efforts towards nonproliferation of weapons of mass destruction and of their delivery vehicles, among others. However, how far NSG, as a group, has followed its own rules is a matter of debate. ${ }^{25} \mathrm{~A}$ related question is whether or not the NSG has created an exclusionary global order.

Another regime, the Zangger Committee, held its first meeting four years before the NSG came into existence. Nonetheless, it is the NSG that has demonstrated greater dynamism and has emerged as more relevant since the end of the Cold War. The Zangger Committee was established to help signatories to the NPT understand the technical issues related to transfers of nuclear materials and technology. However, the committee did not include countries that were not signatories to the treaty.

One such nation was France. The NSG, established as a complement to the committee, brought nations such as France into the control regime (France would subsequently accede to the treaty and also join the Zangger Committee in 1992). Many developing nations believed (and some continue to do so) that the Zangger Committee and the NSG were both regimes for denying technology to the developing world. For example, many scholars from the Global South have stated that these institutions have acted as

${ }^{25}$ China's membership in the group, for example, has been frequently criticized as not strictly adhering to the rules set up by the group's guidelines. Yet, the group went ahead with accepting the membership, ignoring the blatant discrepancies. See Institute of Defence Studies and Analyses (ISDA), Balachandran, G and Kazi, R, Membership Expansion in the Nuclear Suppliers Group, 22 June 2016, at $<$ idsa.in/specialfeature/membership-nuclear-suppliers-group_gbalachandran_220616>（accessed 18 November 2017). 
barricades that blocked the flow of goods and technology to countries pursuing economic development through peaceful nuclear energy programmes. ${ }^{26}$

Some of the prominent authors from the Global South are of the opinion that when an organisation is international, not to mention informal like the NSG, the group's objectives must be internationally acceptable. Therefore, in order for the NSG's decision-making to gain international acceptance, the regime's membership must be representative of the world community. ${ }^{27}$ The group's membership manifests a distinct bias towards the developed world in general and Europe in particular, with over 30 members being European. It must be noted that not all of these belong to the European Union, but only a few of them are classified as 'developing' by the World Bank. Beyond Europe, the developed world gains further representation from Australia, Canada, New Zealand, and the US. Among Asia's four NSG members (China, Japan, Kazakhstan, and South Korea) only two are developing nations. Meanwhile, Latin America is solely represented by Argentina and Brazil, and Africa by South Africa alone.

Though only a few Asian countries qualify as developed today, Asia is a continent that promises to shape a new global order. Moreover, it is a continent with large, fastgrowing economies that will demand a great deal of energy, including nuclear energy. These developing countries, as well as other developing nations have long complained that multilateral export control regimes stunt their economic development. While it is true that even the development of civil nuclear energy has the potential of becoming a hazardous weapon in the hands of a wayward State if not properly regulated, the NSG would nevertheless have to begin to strike a better balance between economic development and nuclear controls. The group should send a signal that it does not oppose development of peaceful nuclear energy, even as it remains strongly opposed to proliferation and proliferation networks.

\section{Conclusion}

In its Advisory Opinion on the Legality of Nuclear Weapons, the International Court of Justice held in 1996 that the mere possession of nuclear weapons would not constitute an unlawful 'threat' to use force contrary to Article 2(4) UN Charter, unless the particular use of force envisaged would be directed against the territorial integrity or political independence of a State or would be inconsistent with the purposes of the United Nations or, in the event that it were intended as a means of defence, such envisaged use of force would violate the principles of necessity and proportionality. ${ }^{28}$ The relevance of this judgment in the present day is withering away as the pragmatic and concerned section of society is rightly pushing towards the complete elimination of nuclear weapons.

However, unfortunately, the chasm between non-proliferation and elimination of nuclear weapons, which may at best be described as an artificial categorization created to

26 See for example - Bulletin of the Atomic Scientists, Nayan, R, Adapting to the $21^{\text {st }}$ Century, 31 December 2012, at <thebulletin.org/paths-forward-nuclear-suppliers-group > (accessed 18 November 2017).

27 Ibid. Also, Brazil for example, argues that institutions such as the UN, the World Bank, the International Monetary Fund (IMF) and others have failed to adequately represent the rising South and developing countries. Even though a part of the NSG, it maintains the view that the global nuclear order is a microcosm of the global order more broadly. See Kassenova, T, "Brazil and the Global Nuclear Order" in Stuenkel, O and Taylor, MM, eds, Brazil on the Global Stage: Power, Ideas and the Liberal International Order (Palgrave Macmillan 2015), 117-142.

28 Article 2(4), United Nations, Charter of the United Nations (1945) 1 UNTS XVI (UN Charter). 
suit the political and economic needs of the stronger nations, has only widened with time. Today the nuclear global order is indeed a neo-colonial order, which seems nowhere to be giving way to the ideals and objectives on which the UN was built and the new international order formed.

There is no doubt that to think nations would negotiate with one another on an equal footing, respecting each other's right to economic and infrastructural development, on any matter of international politics, is nothing but holding on to naive ideals. To think of multilateralism to be invincible is to be far removed from reality. The huge gap that continues to exist between the Global North and South, especially in terms of matters of international policy, is a harsh truth that we all must face. Nevertheless, the nuclear issue today is a matter that needs to be viewed more objectively by the world powers, due to the sheer destructive potential of nuclear weapons. The ongoing crisis in the Middle East on the issue of decertifying the Iran Nuclear Deal, the political onslaught being exchanged between the US and the Democratic Republic of Korea regarding the continued nuclear testing being carried out by the latter despite various UNSC resolutions, the opaque functioning of the Nuclear Suppliers Group, and other similar instances add enough emphasis to this argument.

Elimination of nuclear weapons is a difficult target, which cannot be achieved unless the NWSs consensually act upon it, acknowledging the acute necessity for the same. Nuclear weapons, as the new tools for international political power-play, will lead to perhaps the most dangerous situations humanity has ever faced. 